explain the history of computers and chess, put the match in its proper perspective, report on the day-to-day events of the match, and explain the details of each game. (...)"

\title{
KASPAROV VERSUS DEEPER BLUE: THE ULTIMATE MAN VERSUS MACHINE CHALLENGE
}

\author{
D. King \\ 1997, 112 pp., B.T. Batsford Ltd., London \\ $£$ 9.99, ISBN 0713483229
}

"If a computer can beat the World Champion, a computer can read the best books in the world, can write the best plays, and can know everything about history and literature and people." - Garry Kasparov

"And on February $10^{\text {th }} 1996$, that futuristic vision came true. DEEP BLUE, the IBM chess-playing machine, defeated Garry Kasparov, the reigning world chess champion and arguably the greatest human chess player in the two-thousand-year history of the game, sending shock waves over the world.

"This was the science fiction nightmare come true. In Arthur C. Clarke's 2001: A Space Odyssey, HAL, the spacecraft's computer, defeated the human captain at chess, and then took over the ship. The message was clear. If a computer could defeat the top human being at an activity that has fascinated, frustrated, infuriated, and delighted humans for so many centuries without ever being 'solved', then they were capable of taking on the most complex of problems and, perhaps more sinisterly, they could take charge and control humans. The machines were taking over.

"For dedicated chess players the result was shocking. The mystique of their most cherished game, enjoyed by millions all over the world, had been shattered. Chess-playing computers had already made their mark over the last decade - there are many commercially available programs that play a decent game - but we could always console ourselves that they had profound limitations: 'They do not understand strategy', 'They are only good for shortrange tactics', 'Computers cannot play the simplest endgames', and, if all else failed, 'I lost, but the game is still far too complex for these machines to understand - Kasparov would never fall for such crude play'. That smugness was shattered on that day. That is why it hurt so much.

"For researchers into Artificial Intelligence, DEEP BLUE's defeat of Kasparov was a landmark achievement. The leader of DEEP BLUE's team, Dr. C.J. Tan, said “This is really indeed a historical event. Many records, historical records, have been broken during this event, both for chess as well as the technical community ... this will help us to further develop our system to serve mankind." That was one of the more restrained remarks. Others spoke of DEEP BLUE's victory as 'species defining'. (...)

“On $3^{\text {rd }}$ May 1997 Kasparov sat down in New York to do battle again, though this time with a different opponent, a new and improved model: DEEPER BLUE. (A depressing thought for Kasparov is that he will never face a machine named 'Deepest Blue': year after year, with faster processing, it will go on improving.)

"But why was this event so significant? A computer can shuffle bits of wood across a table with the best of them. So what? Were these closely fought matches a watershed, or had it more to do with the egos of computer programmers? To answer that we have to go into the history of research into Artificial Intelligence and the role that chess played in it."

1 B.T. Batsford Ltd., 583, Fulham Road, London SW6 5BY, United Kingdom. 